University of Nebraska - Lincoln

DigitalCommons@University of Nebraska - Lincoln

Faculty Publications, Department of Psychology

Psychology, Department of

October 2006

\title{
Linking adolescent family and peer relationships to the quality of young adult romantic relationships: The mediating role of conflict tactics
}

\author{
Lisa J. Crockett \\ University of Nebraska-Lincoln, ecrockett1@unl.edu \\ Brandy A. Randall \\ North Dakota State University, Brandy.Randall@ndsu.edu
}

Follow this and additional works at: https://digitalcommons.unl.edu/psychfacpub

Part of the Psychiatry and Psychology Commons

Crockett, Lisa J. and Randall, Brandy A., "Linking adolescent family and peer relationships to the quality of young adult romantic relationships: The mediating role of conflict tactics" (2006). Faculty Publications, Department of Psychology. 236.

https://digitalcommons.unl.edu/psychfacpub/236

This Article is brought to you for free and open access by the Psychology, Department of at DigitalCommons@University of Nebraska - Lincoln. It has been accepted for inclusion in Faculty Publications, Department of Psychology by an authorized administrator of DigitalCommons@University of Nebraska - Lincoln. 


\title{
Linking adolescent family and peer relationships to the quality of young adult romantic relationships: The mediating role of conflict tactics
}

\author{
Lisa J. Crockett \\ University of Nebraska-Lincoln \\ Brandy A. Randall \\ North Dakota State University
}

\begin{abstract}
This study examined the associations between the quality of adolescents' peer and family relationships and the quality of their young adult romantic relationships. Adolescents $(N=253)$ completed self-report measures of their family and peer relationships in grades 10-12; 7 years later, they reported on connectedness, discord, and the conflict tactics used by both partners in their current romantic relationships. Family relationship quality in adolescence predicted the levels of connectedness, discord, and specific conflict behaviors youth reported in their adult romantic relationships. The use of discussion to resolve conflict mediated the association between adolescent family relationships and the level of connectedness in adult romantic relationships. Moreover, use of discussion and physical conflict/threat each partially mediated the effect of family relationship quality on romantic discord. Possible mechanisms linking family of origin relationships to adult romantic relationships are discussed.
\end{abstract}

Keywords: romantic relationships, young adults, conflict strategies, family relationships, peer relationships

This research was funded by grant APR 000933-01 from the Office of Adolescent Pregnancy Programs to Judith R. Vicary, and grant AA 09678-01 from NIAAA to the first author. We gratefully acknowledge the contributions of the participating schools and the project staff of the Rural Adolescent Development Study and the Rural Young Adult Transitions Study. All correspondence concerning this article should be addressed to Lisa J. Crockett, Department of Psychology, 319 Burnett Hall, University of Nebraska-Lincoln, Lincoln, NE 68588-0308, USA; Email: ecrockett1@unl.edu 
Over the last two decades, romantic relationships have emerged as a focal topic of study among scholars in a number of disciplines. Accompanying this shift has been a growing interest in the developmental antecedents of romantic relationships and the processes contributing to relationship quality. Compelling arguments have been made for the influential role of early parent-child and peer relationships in subsequent romantic relationships (Collins \& Van Dulmen, 2006). However, most of the empirical literature has focused on adolescent romantic relationships, with less attention to the early predictors of adult relationship quality. This lacuna is unfortunate, since early adulthood is thought to represent a critical time for the development of romantic relationships. Theories of life-span development identify romantic intimacy (Erikson, 1963) and mate selection (Havighurst, 1972) as central tasks of early adulthood, and, consistent with this notion, young adults place a high priority on finding a long-term partner (Cantor, Acker, \& Cook-Flanagan, 1992). In the present study, we examined the associations between relationships with parents and peers in adolescence and the quality of young adults' romantic relationships.

\section{Young adult romantic relationships}

Romantic relationships become increasingly common during adolescence and early adulthood. By age 15, most adolescents report having had a boyfriend or girlfriend sometime during the past three years (Feiring, 1996), and in the post high-school years most report an ongoing romantic relationship (Brown, 2004). Moreover, romantic partners become increasingly important as a source of support from grade school to the college years (Furman \& Buhrmester, 1992). The nature and quality of romantic relationships also appear to shift with age, in that they become more stable, exclusive and committed in late adolescence and early adulthood (Connolly \& Goldberg, 1999).

Considerable research has addressed the concurrent or short-term predictors of satisfying adult relationships, especially marital partnerships, as well as factors that may contribute to relationship distress and dissolution (e.g., Bradbury, Cohan, \& Karney, 1998). These studies point to the importance of attitudes and behaviors in shaping relationship quality. However, few prospective studies have examined the developmental origins of satisfying romantic relationships in early adulthood. Collins and van Dulmen (2006) propose that experiences in early relationships with parents and peers are carried forward and influence the quality of early romantic relationships. Both parent-child and peer relationships provide opportunities to learn expectations, skills, and behaviors that could carry over into subsequent romantic relationships, potentially affecting relationship quality.

\section{Family relationships and adult romantic relationships}

Families are considered a crucial training ground for romantic relationships (Tallman, Burke, \& Gecas, 1998). According to social learning theory, parents serve as important role models for their children. By observing their parents' marital relationship, children may learn specific behavior patterns (e.g. conflict resolution strategies) and develop general expectations for appropriate behavior in romantic relationships (e.g., rules for expressing affection), as well as scripts for their own heterosexual relationships (Feldman, Gowen, \& Fisher, 1998). In line with this notion, Martin (1990) found that conflict between parents was associated with aggressive and avoidant patterns in parentchild conflict, patterns that were reproduced in the children's conflict with romantic partners. However, longitudinal studies have provided relatively little support for effects of observational learning on the quality of subsequent romantic relationships (Capaldi \& Clark, 1998; Simons, Lin \& Gordon, 1998). Instead, the subjective experience of participating in positive family relationships appears more central (Conger, Cui, Bryant, \& Elder, 2000).

Longitudinal research has documented a link between positive parent-child relations in adolescence and the quality of later romantic relationships. German youth who reported a reliable alliance with parents in adolescence also reported greater feelings of connectedness and attraction to their romantic partners 6 years later (Seiffge-Krenke, Shulman, \& Klessinger, 2001). In a US sample, adolescents' reports of family interaction patterns predicted their happiness and distress in romantic relationships as young adults (Feldman et al., 1998). Furthermore, adolescents' ratings of the quality of their relationships with parents have been associated with the perceived quality of their romantic and sexual relationships in emerging adulthood (Joyner \& Campa, 2006). Using observer ratings of family interactions, Conger et al. (2000) found that adolescents' experiences of supportive, involved parenting were associated with their reported level of satisfaction and commitment in romantic relationships at age 20. Thus, adolescents who experience positive family relationships appear to be advantaged in subsequent romantic attachments. These studies lead to the expectation that supportive family relationships in adolescence will predict better romantic relationships in early adulthood.

\section{Peer relationships and romantic relationships}

Peer relationships are a second arena for learning about romantic relationships. Friendship theorists (Sullivan, 1953) have emphasized the role of close preadolescent friendships in the emerging capacity for intimacy; in turn, intimacy with same-sex friends may lay the foundation for romantic intimacy (Connolly \& Goldberg, 1999). Because peer relationships involve persons of similar age, social status, and competencies, they tend to be egalitarian and thus afford opportunities for co-operation, mutual altruism, and reciprocity that are unlikely 
to be present in children's relationships with adults (Furman, 1999). Peer relationships also offer lessons in conflict resolution. Because peers are similar in status and power, mutual negotiation is needed to resolve conflicts. Furthermore, peer relationships are voluntary and partners can opt out, so noncoercive strategies for resolving conflict are likely to predominate (Laursen, 1993). Adolescents tend to use negotiation strategies to manage conflict more than younger children do (von Salisch \& Vogelgesang, 2005), and such skills may prove crucial in adult relationships, including romantic partnerships.

Consistent with the proposed link between peer relationships and romantic relationships, correlations have been reported between the quality of close friendships and romantic relationships in adolescence (e.g., Connolly, Furman, $\&$ Konarski, 2000). However, the role of adolescent peer relationships in the more mature romantic relationships of adulthood has rarely been studied. In a sample of German youth, significant bivariate associations emerged between adolescents' reported intimacy in close friendships and the level of connectedness and attraction they reported towards romantic partners in adulthood; however, this association was not seen in multivariate models that also included parent-adolescent relationship quality (Seiffge-Krenke et al., 2001). Thus, although the linkage between adolescent peer and romantic relationships has been supported, the role of adolescent peer relationships in adult romantic relationships has not been established. One goal of the present study was to assess the unique contributions of adolescent peer and family relationships and their relative importance as predictors of adult romantic relationship quality.

\section{Gender differences in predictors of romantic relationship quality}

A second goal was to examine gender differences in the predictive role of peer and family relationships. Research indicates that girls are more 'relationship oriented' than boys and more invested in developing intimate relationships (see Block, 1983, for a review). Compared to boys, girls are more relationship focused in their goals and anticipate greater distress when their relationships are threatened (Nelson \& Crick, 1999). Girls also emphasize care and attachment in their relationships more than boys do (Shulman \& Scharf, 2000), and women are thought to take greater responsibility for the maintenance of adult romantic relationships (Wood, 2000). Thus, although both partners contribute to the quality of romantic relationships, women may be especially motivated to do so, and their relational competence may have a greater impact on the relationship. If so, the negotiation skills and conflict tactics that women bring to the relationship may prove more influential than men's in determining adult relationship quality.

There is also empirical evidence that the quality of peer and family relationships is differentially predictive of romantic relationship quality for women versus men. For example, family characteristics such as respect for privacy and flexible control more strongly predict women's than men's romantic at- tachment style and happiness in love (Feldman et al., 1998). Moreover, girls and boys' peer relationships emphasize different styles of relating and may afford different opportunities for developing relationship skills (Leaper, 1994). Studies of preadolescents indicate that boys' peer groups are more hierarchical whereas girls' are more egalitarian, with a greater emphasis on joint decision making and interpersonal harmony (Maccoby, 1995). Thus, girls' peer relationships may provide more opportunities to learn practices such as turn taking and shared decision making which could contribute to harmonious romantic relationships. Based on these findings, we expected associations between the quality of adolescents' family and peer relationships and the quality of their adult romantic relationships to be stronger for females than males.

\section{Conflict tactics}

A third goal of the present study was to examine conflict behaviors as possible mediators of the association between adolescent interpersonal relationships and young adult romantic relationships. Conflict is a central feature of close relationships, and conflict resolution skills have been linked empirically to adult relationship quality and satisfaction (Bradbury et al., 1998). Certain conflict management behaviors appear to be beneficial for healthy romantic relationships. In a study of couples followed over a 2 -year period, higher marital satisfaction was associated with greater use of mutual discussion and less avoidance and coercion in resolving conflict (Noller \& Feeney, 1998). Similarly, research with college students has shown that greater relationship satisfaction is associated with use of integrative conflict resolution strategies that allow both partners to meet their goals (Pistole, 1989). Thus, conflict behaviors in which both partners' perspectives are considered appear to be important for maintaining satisfying relationships. In contrast, attempts by partners to dominate each other and impose their will may be detrimental.

Conflict tactics may be learned through experiences with family members and peers. In a cross-sectional study, conflict resolution styles reported by late adolescents in their interactions with parents (e.g., attack, avoidance, or compromise) were associated with the styles they reported using with romantic partners (Reese-Weber \& Bartle-Haring, 1998). In a prospective study, Conger et al. (2000) found that adolescents who experienced more nurturant-involved parenting subsequently showed greater warmth and less hostility in their interactions with a romantic partner. In turn, these affective displays predicted the quality of their adult romantic relationships. Similarly, peer relationships afford opportunities for learning conflict management, particularly noncoercive strategies (Laursen, 1993). Conflict tactics developed in adolescents' family and peer relationships could carry over into their adult romantic relationships and help explain associations between the quality of adolescent interpersonal relationships and adult romantic relationships. 
In summary, most developmental research predicting the quality of young adults' romantic relationships has tended to focus on either family relationships or peer relationships, making it difficult to gauge their relative importance in predicting the quality of romantic relationships. Additionally, most studies have utilized concurrent or retrospective measures of adolescent relationships rather than examining the impact of these relationships prospectively. Finally, few prospective studies have examined specific processes through which early relationships influence the quality of adult romantic relationships. The present study addressed these gaps in the literature, using data from a sample of youth followed from adolescence into adulthood. Based on prior theory and research, peer and family relationships were each expected to show associations with adult relationship quality; the relative importance of these adolescent relationships in predicting adult relationship quality was also explored. Furthermore, we tested whether conflict behaviors mediated associations observed between the quality of adolescent interpersonal relationships and adult romantic relationships. Finally, we examined gender differences in the relations between adolescent peer and family relationships and young adult romantic relationships, anticipating somewhat stronger associations for females than males. We included controls for several demographic variables likely to be associated with romantic relationship quality, including age and adolescent family structure (Amato \& Keith, 1991; Connolly \& Goldberg, 1999; Shulman \& Scharf, 2000).

\section{Method}

\section{Design}

Data came from a longitudinal investigation of adolescent development among rural youth. The study employed a cohort-sequential design (Baltes, Reese \& Nesselroade, 1977 ) in which three grade-cohorts of adolescents from a single rural school district were surveyed annually through the end of high school. Participants were in 7th, 8th, and 9th grades when the study began in 1985. Periodic follow-ups were conducted during the post high-school years, for a total of 8 waves of data. Data for the present study came from the fourth annual survey in 1988 - when the participants were in grades 10-12 (Time 1) - and the young adult follow-up in 1995-96 (Time 2). We chose senior high school as the initial time point because it is unclear when adolescents develop stable relationship styles and we wanted to maximize the possibility of capturing stable behavior patterns that would carry over into adulthood.

\section{Procedure}

During the adolescent phase of the study, participants completed a written survey each fall administered by project personnel. Boys and girls were surveyed at school in separate rooms. To ensure confidentiality, teachers and school administrators were excluded from the survey process, no names were used on questionnaires, and students were monitored during the survey. Students whose parents refused consent were excluded from data collection. Incentives for participation were offered in the form of raffle items such as sweatshirts and football tickets. Over $90 \%$ of eligible students participated in the initial survey in 1985 (Vicary, Klingaman, \& Harkness, 1995). In 1995, participants were recontacted for the young adult follow-up. Members of all three cohorts were mailed a survey covering multiple facets of their lives including their romantic relationships.

\section{Sample}

The sample came from a single school district in the eastern United States serving a geographically isolated, low-to-middle income rural community. Residents were primarily White and of European descent. The area was considered to be economically and educationally disadvantaged. Data from the 1980 census (the last census prior to the onset of the study) indicated that the primary occupational categories were laborer and technical/clerical. The median household income was $\$ 14,500$, and $12 \%$ of households were below the poverty level.

The present analyses included youth who participated in the fourth annual survey (Time 1) and the young adult follow-up (Time 2), and who reported a current romantic relationship at Time 2. Of the 531 adolescents present at Time 1, $357(67.2 \%)$ participated in the young adult follow-up 7 years later. Overall, $75.9 \%$ of the Time 2 sample reported a romantic relationship. Because gay, lesbian and bisexual youth may face unique issues in their romantic relationships (Savin-Williams, 1996), young adults who self-identified as nonheterosexual or who reported sexual attraction to members of the same sex $(n=18)$ were excluded from analysis. The final analytic sample included 253 young adults (106 males and 147 females). The participants were in grades $10-12($ mean age $=16.13, S D=.87)$ at Time 1 and between the ages of 21 and $26(M=$ 23.25, $S D=.94)$ at Time 2 .

To examine attrition effects, youth present at Time 1 who did and did not participate in the young adult follow-up were compared using $t$-tests. Results indicated that those in the longitudinal sample were disproportionately female, $t(529)=-4.40, p<.001, d$ $=-.41$ and slightly younger, $t(529)=-2.17, p<.05, d=-.20$, than those who attrited; they were also more likely to have resided in intact families (two biological parents) in high school, $t(528)=-2.11, p<.05, d=-.19$. The differences were not large, with effect sizes ranging from small (for age and family structure) to small-medium (for gender). Notably, no significant differences were found for quality of family relationships, peer relationships, or mother's education.

\section{Measures}

Time 1 measures included family and peer relationship quality and demographic controls. Time 2 measures included conflict behaviors and romantic relationship quality. For multi-item scales, scale scores were computed for youth with data on at least $75 \%$ of the items.

Quality of adolescent family and peer relationships. The quality of adolescents' relationships with parents and peers was assessed using the Family Relations and Peer Relations subscales of the Self-Image Questionnaire for Young Adolescents (SIQYA; Petersen, Schulenberg, Abramowitz, Offer, \& Jarcho, 1984). The Family Relations 
scale contains 17 items (e.g., 'I can count on my parents most of the time'); the Peer Relations scale contains 10 items (e.g., 'I do not have a particularly difficult time making friends'). Responses were made on a 6-point Likert-type scale ranging from 1 (very strongly agree) to 6 (very strongly disagree). Items for each scale were averaged, with higher scores indicating better relationship quality. At Time 1, coefficient alpha was .89 for Family Relations and .85 for Peer Relations.

Young adult relationship status and duration. Young adults who reported being in a romantic relationship were asked about the status of that relationship (e.g., whether they were dating, committed but not living together, living together but not engaged or married, engaged, or married). They also reported the duration of the relationship. Responses could range from less than 6 months to 5 years or more.

Young adult romantic relationship quality. The quality of participants' current romantic relationships was assessed with a 16-item scale adapted from Braiker and Kelly's (1979) questionnaire on intimacy and commitment between partners. Twelve items from the original measure were supplemented with four additional items ('How stressful is your relationship with your partner?', 'How satisfied are you with your relationship with your partner?', 'How much do you confide in your partner?', 'How well are things going between you and your partner?'). For this study, responses were coded on a scale ranging from 1 to 7 , with anchor labels depending on the nature of the item. Factor analysis using principal components analysis with oblique (promax) rotation suggested a two-factor solution: A 10-item connectedness factor (e.g., 'How close do you feel to your partner?' $\alpha=.92$ for women and .93 for men) and a 6-item discord factor (e.g., 'How often do you feel angry or resentful toward your partner?' $\alpha=.88$ for women and .87 for men). The two factors explained $63.16 \%$ of the variance and were moderately intercorrelated $(r=-.44)$. For each scale, items were averaged with higher scores indicating more connectedness (discord)

Conflict tactics. The measure of conflict behaviors was developed for this study. Participants were asked, 'When you and your partner argue, how often do each of the following things happen?' Responses were coded on a 4-point scale ranging from 1 (never) to 4 (most of the time). The 11 items formed three subscales, based on a principal components factor analysis with oblique (promax) rotation. Physical Conflict/Threat ( $42 \%$ of the variance, 6 items, e.g., 'My partner slaps or hits me,' $\alpha=.85$ for women and .82 for men; Discussion (13.49\% of the variance, 3 items; e.g., 'We talk things over calmly,' $\alpha=.82$ for women and .73 for men ); and Verbal Conflict ( $9.55 \%$ of the variance, 2 items: 'I yell,' $\alpha=.83$ for women and .76 for men). For each scale, items were averaged with higher scores indicating greater use of that tactic. The three subscales were moderately intercorrelated (absolute values of $r$ ranged from .42 to .49 ).

Demographic controls. Gender and age were taken from the young adult follow-up (Time 2); family structure was assessed at Time 1. Family structure was coded as 1 (two biological parents, $n=170$ ) or 0 (other, $n=82$ ).

\section{Results}

\section{Preliminary analyses}

To assess the seriousness of the young adults' romantic relationships, we examined relationship status and duration. Only $9.5 \%$ of the young adults said they were dating, almost $60 \%$ were either engaged or married, and the remainder reported intermediate levels of commitment. Regarding duration, $20 \%$ of the participants reported they had been with their partner for less than 1 year; $46 \%$ between 1 and 5 years, and $34 \%$ for 5 years or more. From these data, it appears that most of the relationships were long-term ones. A comparison between young adults who were engaged or married and those in other relationship statuses indicated that, as would be expected, those who were engaged $/$ married $(M=6.25, S D=.92)$ reported significantly more connectedness to their romantic partner than those in other relationship categories $(M=5.77$, $S D=1.01), t(202)=-3.85, p<.001, d=.50$. They also reported more verbal conflict $(M=2.63, S D=.85$ vs. $M=2.34, S D=.86), t(245)=-2.61, p<.01, d=.34$ and more physical conflict/threat $(M=1.32, S D=.55$ vs. $M=1.18, S D=.31), t(243)=-2.52$, $p<.05, d=.31$. Participants in more advanced relationship stages were also older $(M$ $=23.37, S D=.97$ vs. $M=23.06, S D=.86), t(228)=-2.64, p<.01, d=.34$ and more likely to be female, $\chi^{2}(1, N=253)=4.61, p<.05$, compared to those in other stages.

Table 1 shows the means, standard deviations, and intercorrelations of the main study variables. There were no significant gender differences in adolescent peer and family relationship quality or on any measures of adult relationship quality. Family relationship quality was positively correlated with connectedness and use of discussion to manage conflict and negatively correlated with discord and physical conflict threat; it was not significantly correlated with verbal conflict. Peer relationship quality was significantly (and negatively) associated only with the frequency of physical conflict/threat. All three conflict behaviors were significantly correlated with connectedness and discord. Quality of family and peer relationships were moderately correlated.

\section{Regressions predicting adult relationship quality}

Multiple regression analyses were used to examine the predictive relations between the quality of family and peer relationships in adolescence and the quality of romantic relationships in early adulthood. Age, gender, and family structure were included in the first step; quality of adolescent family relationships was included in the second step; and quality of peer relationships was added in the third step. Typically, children first experience close relationships within the family and later develop relationships with peers; this sequence is reflected in our regression models. We also tested all twoway interactions among family relationships, peer relationships, and gender in a fourth step, and the three-way interaction in a fifth step. To reduce unnecessary collinearity between interaction terms and main effects, scores for family relationships and peer relationships were centered prior to creating interaction terms (Aiken \& West, 1991). None of the three-way interactions was significant, so they are not presented.

The regressions predicting general relationship quality (connectedness and discord) are summarized in Table 2. For level of connectedness, Step 1 was not significant, and none of the control variables showed a significant effect. In Step 2, the change in $R^{2}$ 


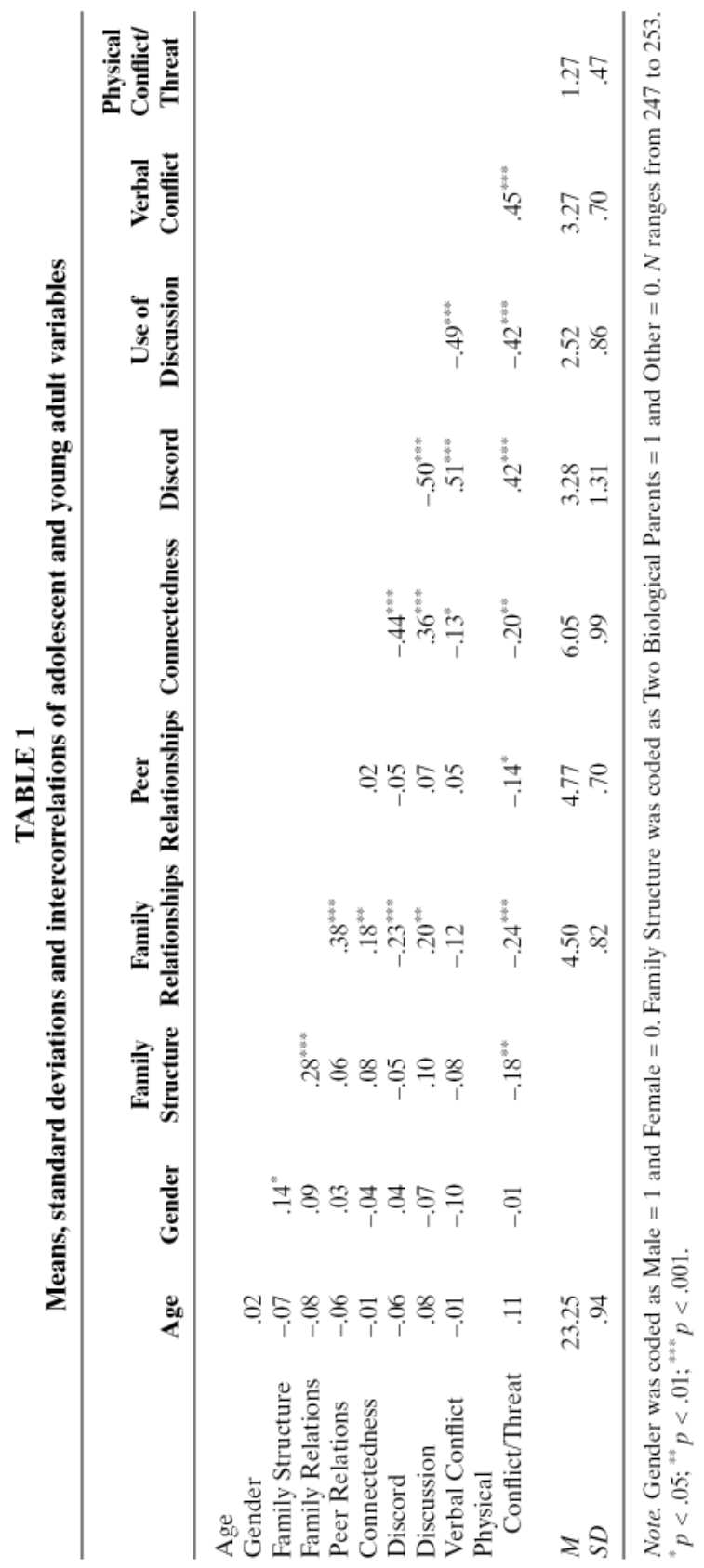

was significant and better family relationships predicted greater feelings of connectedness towards the romantic partner. In Step 3, the addition of peer relationships did not yield a significant increase in $R^{2}$. Adding the two-way interactions in Step 4 also failed to significantly increase $R^{2}$

For level of discord, Step 1 was not significant; however, in Step 2 the change in $R^{2}$ was significant and better family relationships were associated with less discord. Step 3 (adding peer relations) did not significantly increase $R^{2}$. Step 4 (two-way interactions) was not associated with a significant increase in $R^{2}$, but the gender $\times$ peer interaction was significant. To interpret this interaction, simple slopes analyses (Aiken \& West, 1991) were conducted for boys and girls. The slope was negative for girls, $b=$ $.13, p<.10$, but positive for boys, $b=.18, p<.10$.

Parallel regression analyses were conducted to examine the predictive relations between adolescent peer and family relationships and young adult conflict behaviors (see Table 3). More positive adolescent family relationships predicted greater use of discussion to resolve conflict; however, the quality of peer relationships and the two-way interactions were not significant. For verbal conflict, none of the steps was significant For physical conflict/threat, the influence of family relationship quality was significant in Step 2. Peer relationship quality was nonsignificant (Step 3), but the gender X peer interaction was significant in Step 4. Simple slopes analyses for boys and girls indicated that the effect of peer relationships was negative for girls, $b=-.16, p<.10$, but positive for boys, $b=.11, p>.10$.

To determine whether the order of entry of peer and family variables affected the results, all of the regression models in Tables 2 and 3 were repeated, with peer relationships entered in Step 2 and family relationships in Step 3. With one exception, changing the order of entry did not alter the pattern of results. The exception was physical conflict/threat. In this case, peer relationship quality showed a significant effect when

TABLE 2

Regressions predicting the quality of adult romantic relationships

\begin{tabular}{|c|c|c|c|c|c|c|c|}
\hline & \multicolumn{3}{|c|}{ Connectedness } & \multicolumn{4}{|c|}{ Discord } \\
\hline & Step1 & Step 2 & Step 3 & Step 1 & Step 2 & Step 3 & Step 4 \\
\hline Age & -.01 & .01 & .01 & -.07 & -.09 & -.09 & -.10 \\
\hline Gender & -.06 & -.07 & -.07 & .04 & .04 & .04 & .04 \\
\hline Family Structure & .09 & .04 & .04 & -.06 & -.01 & -.01 & .01 \\
\hline Family Relationships & & $.17^{* *}$ & $.19^{* *}$ & & $-.22^{* * *}$ & $-.24^{* * *}$ & $-.21^{*}$ \\
\hline Peer Relationships & & & -.06 & & & .03 & -.13 \\
\hline Gender $\times$ Fam Rels & & & & & & & .01 \\
\hline Gender $\times$ Peer Rels & & & & & & & $.21^{\circ}$ \\
\hline Fam Rels $\times$ Peer Rels & & & & & & & -.09 \\
\hline$R^{2}$ at each step & .01 & .04 & .04 & .01 & .06 & .06 & .08 \\
\hline$F$ & .82 & 2.33 & 2.01 & .74 & $3.54^{\circ 6}$ & $2.87^{\circ}$ & $2.76^{\circ 0}$ \\
\hline$d f$ & 3.245 & 4.244 & 5,243 & 3.245 & 4.244 & 5.243 & 8.240 \\
\hline$F_{\text {change }}$ & .82 & $6.80^{\circ}$ & .71 & .74 & $11.86^{\circ 606}$ & .23 & 2.50 \\
\hline
\end{tabular}

Note. Standardized regression weights. Gender was coded as Male $=1$ and Female $=0$. Family Structure was coded as Two Biological Parents $=1$ and Other $=0$.

$" p \leq .05 ; * * \leq .01 ;{ }^{* * *} p \leq .001$. 


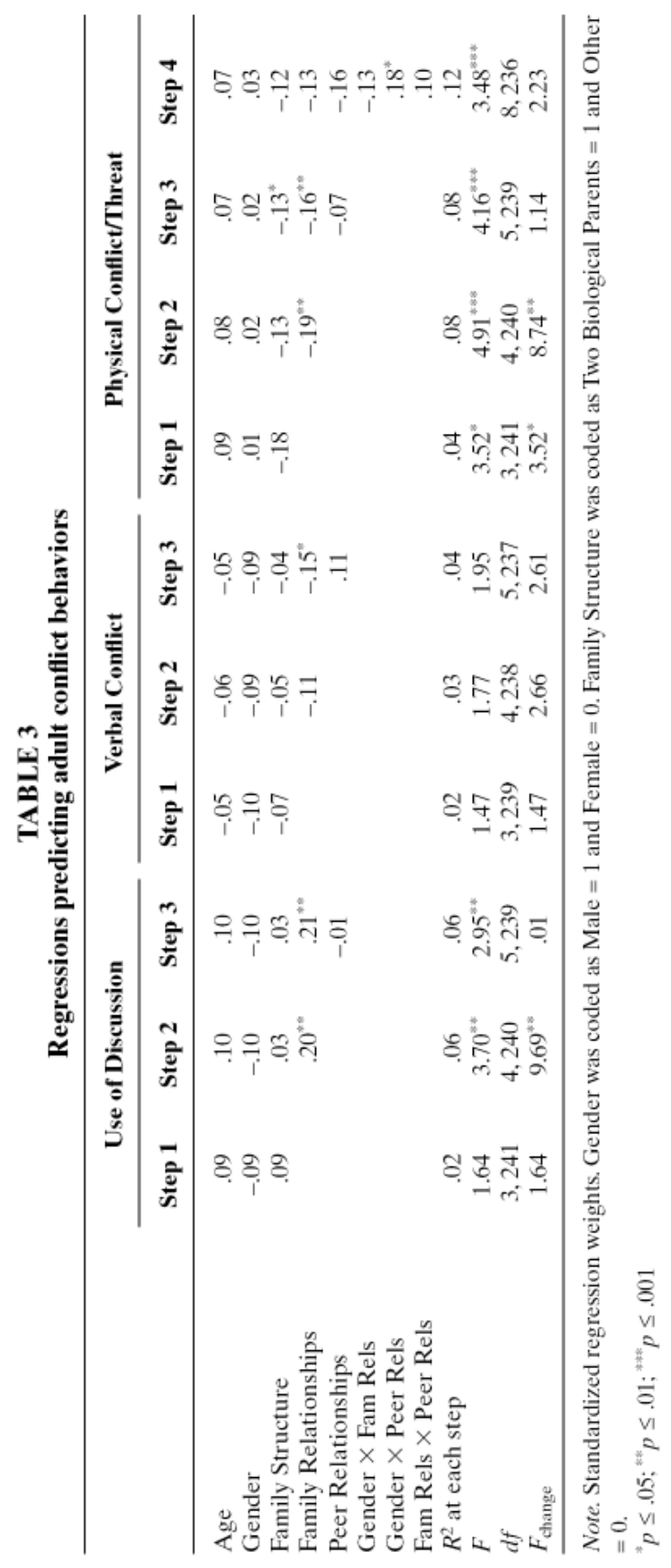

entered in Step $2\left(\beta=-.14, R^{2}=.06, F(4,240)=3.75, p<.01\right)$. Adding family relations in Step 3 resulted in a significant increase in $R^{2}\left(R^{2}=.08, F(5,239)=4.12, p<\right.$ $\left..001, F_{\text {change }}=5.50, p<.05\right)$. When both peer and family relations were in the model, only family relations was significant.

\section{Conflict behaviors as mediating variables}

The remaining question was whether the observed associations between the quality of adolescent family relationships and the quality of young adult romantic relationships could be attributed to specific conflict tactics. To support mediation, there must be an initial association between family relationship quality and romantic relationship quality as well as between family relations and the potential mediator (conflict behavior). Moreover, when the conflict behavior is added to the model predicting romantic relationship quality from family relations, the effect of the conflict behavior must be significant and the effect of family relations must be nonsignificant or substantially reduced (Baron \& Kenny, 1986). Table 4 presents regression results showing the association between family relationship quality and romantic relationship quality (connectedness or discord) before and after each conflict behavior was entered into the equation. The base model, which included controls and family relationships, is presented first, followed by separate models in which a single conflict behavior was added: use of discussion (Model 1); physical conflict/threat (Model 3). Because verbal conflict was not associated with family relations (see Table 3 ), it was not a potential mediator; however, the regression results for this behavior are presented for completeness.

Perceptions of connectedness. In the base model (see Table 4), family relationships significantly predicted perceptions of connectedness. When discussion was added (Model 1), it was also significant $(\beta=.35, p<.001)$, and the association between family relationships and connectedness became nonsignificant, consistent with mediation. A Sobel test (Preacher \& Leonardelli, 2001) confirmed that the indirect effect (from family relationship quality through use of discussion to perceived connectedness) was significant $(\mathrm{z}=2.69, p<.01)$. In separate analyses, physical conflict/threat significantly predicted connectedness (Model $3, \beta=-.17, p<.05$ ), but the effect of family relationships was not substantially reduced and remained significant. Thus, only use of discussion was supported as a mediator of the association between family relationships and connectedness.

Perceptions of discord. Family relationships significantly predicted discord in the base model $(\beta=-.23, p<.001)$. In addition, each of the three conflict behaviors was a significant predictor when added to the base model (discussion in Model 1; verbal conflict in Model 2; and physical conflict/threat in Model 3). In each case, however, the effect of family relations on discord remained significant. Thus, no conflict behavior fully accounted for the association between family relationships and discord. However, Sobel tests indicated that the indirect effects through use of discussion and physical conflict/threat were each significant $(\mathrm{z}=-2.89, p<.01$ and $\mathrm{z}=-2.68, p<.01$, respectively). Thus, use of discussion and physical conflict/threat each partially mediated the association between family adolescent family relations and the quality of adult romantic relationships. 


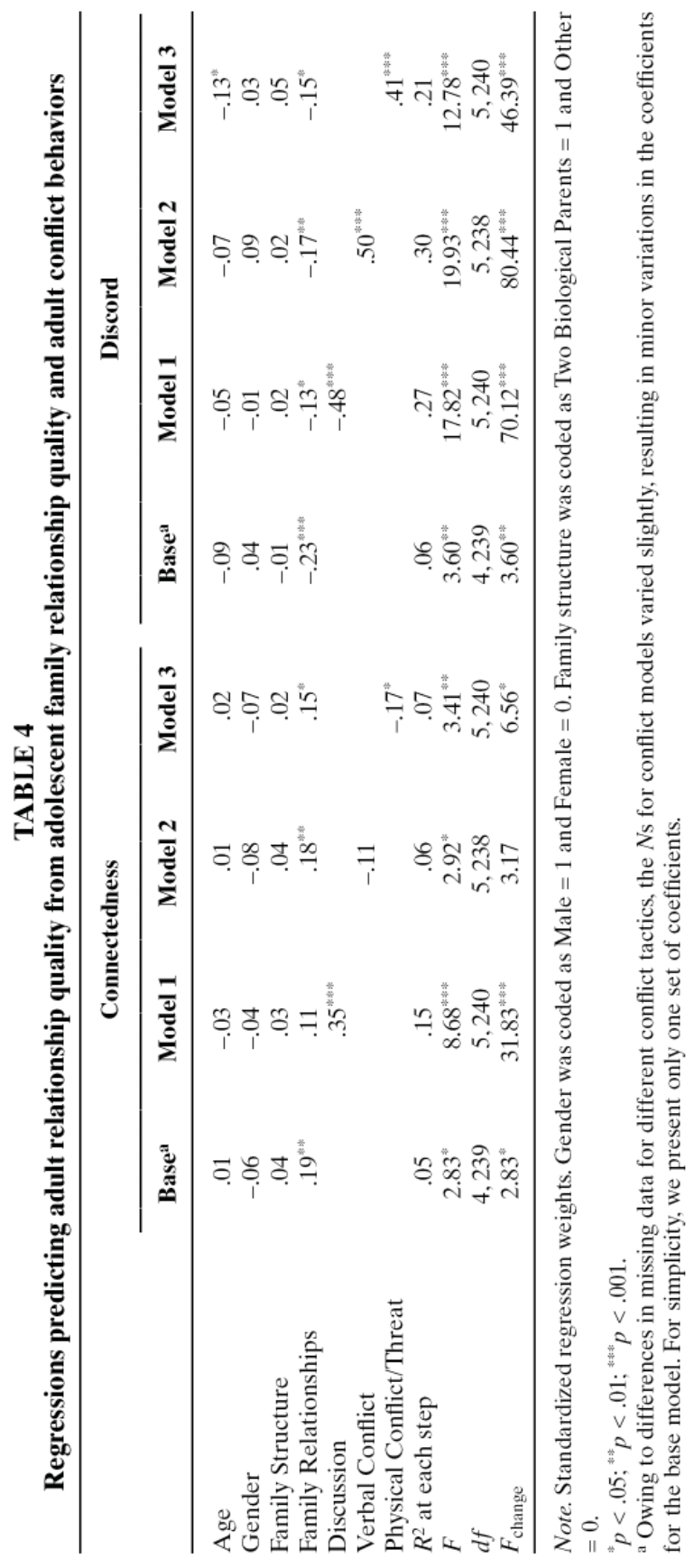

\section{Discussion}

Despite recent interest in the predictors of satisfying romantic relationships, few studies have examined the prospective relations between the quality of adolescent peer and family relationships and the quality of adult romantic relationships or tested possible mediators of these associations. Our study extended prior research by comparing the relative contributions of adolescent family and peer relationships to adult relationship quality and by examining conflict behaviors as possible mediators of these associations. Results supported the hypothesized association between the quality of adolescents' family relationships and the quality of their adult romantic relationships. The role of family relationships was pervasive, predicting indicators of general relationship quality (connectedness and discord) in adulthood as well as specific conflict behaviors. Moreover, conflict tactics helped explain the association between the quality of adolescent family relationships and adult romantic relationships.

The results for family relationships are consistent with the handful of longitudinal studies that have documented associations between family practices or parent-child relationships in adolescence and the quality of young adults' romantic relationships (e.g., Collins \& Van Dulman, 2006; Conger et al., 2000). Thus, evidence of the long-term importance of adolescents' family relationships continues to accumulate. The consistency across studies is noteworthy, especially in light of the diverse aspects of romantic relationships assessed, the different samples used, and the distinct measures employed.

In contrast, adolescent peer relationships appeared to have little impact on adult romantic relationships. The quality of adolescent peer relationships was associated with only one relationship behavior - the amount of physical conflict/threat between partners — and this effect became nonsignificant when the quality of adolescent family relationships was controlled. However, two significant interactions with gender suggested divergent patterns for girls and boys, such that good peer relationships predicted less physical conflict/threat and lower discord for girls but the opposite for boys. Because within-gender associations were not significant, these significant interactions should be in terpreted with caution. Nonetheless, the possibility of distinct peer effects for girls and boys deserves attention in future studies.

The general absence of main effects of peer relationships found in this study contrasts with studies examining the role of friendships in adolescent romantic relationships (e.g., Collins \& Van Dulmen, 2006; Connolly et al., 2000; Furman, 1999). However, it is consistent with some recent research on young adults, in which the quality of adolescent-parent relationships but not adolescent friendships had a significant unique effect on adult romantic relationships (Seiffge-Krenke et al., 2001). One possible explanation of this pattern is that the predictors of young adult and adolescent romantic relationships differ. Peer relationships may predict the quality of romantic relationships in adolescence when young people are in the early stages of learning about romantic 
attachments. However, as more serious attachments develop in early adulthood potentially leading to long-term partnerships, lessons from the family of origin may predominate. This explanation is in keeping with the developmental model of romantic relationships proposed by Furman and Wehner (1994, 1997) in which the salient dimensions of romantic relationships change with age, perhaps leading to age-related differences in predictors of relationship quality. In future research, the predictors of adolescent and young adult romantic relationships could be directly compared.

The present results provide support for the hypothesis that adolescent family relationships influence adult romantic relationships by fostering interpersonal behaviors that affect romantic relationship quality. Use of discussion to resolve conflict (a constructive approach) mediated the association between the quality of adolescent family relationships and adult romantic connectedness. Additionally, greater use of discussion and less physical conflict/threat each partially mediated the association between family relationships and romantic discord. Such findings build on research showing that conflict strategies in which the views of both partners are acknowledged are associated with more satisfying romantic relationships (Noller \& Feeney, 1998; Pistole, 1989). They are also consistent with studies showing that conflict behaviors partially mediate the association between attachment style and relationship satisfaction among married couples (e.g., Feeney, 1994). From a practical standpoint, our results suggest that early interventions to promote satisfying romantic relationships might teach constructive approaches to conflict resolution, such as talking issues over calmly and taking the partner's perspective, as well as emphasize the need to avoid coercive strategies such as threats or physical aggression.

The finding that conflict tactics helped account for the longitudinal associations between adolescents' family relationships and the quality of their adult romantic relationships is consistent with a socialization model in which young people learn relationship behaviors through family interactions. In a similar vein, Conger et al. (2000) found that more nurturant-involved parenting in adolescence was associated with greater warmth and less hostility in later interactions with a romantic partner, which in turn predicted the quality of adult romantic relationships. In the present study, we focused on conflict behaviors rather than affective expressions and found corresponding support for a mediational model. Thus, it appears that both affective and behavioral aspects of relating may develop in the context of family relationships and carry over into adult romantic relationships. However, the specific processes producing continuity have yet to be determined. Although our results and those reported by Conger and colleagues are compatible with a socialization perspective, other processes could also be involved. For example, good family relationships might create positive relationship expectations or positive internal working models, which in turn increase the likelihood of positive interactions and constructive conflict strategies (Cassidy, 2000; Feeney \& Noller, 1990). The interplay of these dis- tinct processes in explaining the connection between adolescent family relationships and adult romantic relationships awaits future studies.

The present results provide evidence of longitudinal effects of adolescent family relationships on young adult romantic relationships, but the amount of variance explained by adolescent variables was quite modest. Including young adult conflict measures substantially increased the amount of variance accounted for, but these variables were assessed concurrently with romantic relationship quality, perhaps inflating the associations. Finding significant associations over a 7-year period is noteworthy in itself, given the attenuation of associations over extended periods and the fact that the study spanned a time of developmental transition from adolescence to adulthood, which increases the potential for discontinuity. Moreover, the concordance of our results with other recent studies (e.g., Conger et al., 2000; Joyner \& Campa, 2006) bolsters confidence in the importance of adolescent family relationships. At the same time, the present modest associations suggest that factors not measured here also contribute to adult relationship quality. For example, our data tapped the perspective of only one partner, but there is evidence that the expectations, attitudes, and personality characteristics of both partners shape relationships (Robins, Caspi, \& Moffitt, 2000).

Several other caveats should be kept in mind when interpreting the results. The available measures of adolescent interpersonal relationships were global indicators of relationships, and more differentiated measures of parent-child and peer relationship quality might have yielded greater explanatory power. In particular we measured the quality of peer relationships in general rather than the quality of close friendships. Additionally, data from multiple reporters and from observations of couple interactions would round out the picture of young adult relationships that emerged in this study. Attrition effects, although small, could have influenced the results; for example, the higher attrition of males (especially those with poor relationships) could have obscured gender differences in relationship quality. Finally, the present sample came primarily from lower- to middle-class families. Although there is no a priori reason to expect processes influencing romantic relationship quality to differ by socioeconomic status, the possibility of social class differences should be examined.

In future studies, researchers might take a more differentiated look at family relationships, examining the effects of particular dyadic relationships (mother-adolescent, father-adolescent, sibling) on adult romantic relationships. Additionally, it might be useful to examine relationship behaviors other than conflict tactics which could be learned in the family (e.g., ways of expressing affection). Finally, studies could include multiple processes through which the quality of adolescent family relationships may influence later romantic relationships. By sorting out the relative roles of internal working models, observational learning, and acquired social skills, it may be possible 
to build a more complete picture of how family relationships in adolescence shape young adults' romantic relationships.

The present findings add to the emerging developmental literature on young adult romantic relationships, underscoring the importance of good adolescent family relationships for the development of satisfying romantic attachments in adulthood. They also highlight the greater relative influence of early family relationships, as compared to peer relationships, on adult romantic relationships. Finally, the results point to conflict tactics as a possible conduit through which positive family relationships influence future romantic relationships.

\section{References}

Aiken, L. S., \& West, S. G. (1991). Multiple regression: Testing and interpreting interactions. Newbury Park, CA: SAGE Publications.

Amato, P. R., \& Keith, B. (1991). Parental divorce and adult well-being: A meta-analysis. Journal of Marriage and the Family, 53, 43-58.

Baltes, P. B., Reese, H. W., \& Nesselroade, J. R. (1977). Life-span developmental psychology: Introduction to research methods. Belmont, CA: Brooks/Cole.

Baron, R. M., \& Kenny, D. A. (1986). The moderator-mediator variable distinction in socia psychological research: Conceptual, strategic, and statistical considerations. Journal of Personality and Social Psychology, 51, 1173-1182.

Block, J. H., (1983). Differential premises arising from differential socialization of the sexes: Some conjectures. Child Development, 54, 1335-1354.

Bradbury, T. N., Cohan, C. L., \& Karney, B. R. (1998). Optimizing longitudinal research for understanding and preventing marital dysfunction. In. T. N. Bradbury (Ed.), The de velopmental course of marital dysfunction (pp. 279-311). New York: Cambridge University Press.

Braiker, H. B., \& Kelly, H. H. (1979). Conflict in the development of close relationships. In R. Burgess \& T. Huston (Eds.), Social exchange in developing relationships (pp. 135168). New York: Academic Press.

Brown, B. B. (2004). Adolescents' relationships with peers. In R. M. Lerner \& L. Steinberg (Eds.), Handbook of adolescent psychology (pp. 363-394). New York: Wiley.

Cantor, N., Acker, M., \& Cook-Flanagan, C.(1992).Conflict and preoccupation in the intimacy life task. Journal of Personality and Social Psychology, 63, 644-655.

Capaldi, D. M., \& Clark, S. (1998). Prospective family predictors of aggression towards female partners for at-risk young men. Developmental Psychology, 34, 1175-1188.

Cassidy, J. (2000). Adult romantic attachments: A developmental perspective on individual differences. Review of General Psychology, 4, 111-131.

Collins, W. A., \& Van Dulmen, M. (2006). The course of true love(s) . . : Origins and pathways in the development of romantic relationships. In A. Crouter \& A. Booth (Eds.), Romance and sex in emerging adulthood: Risks and opportunities (pp. 63-86). Mahwah, NJ: Lawrence Erlbaum Associates.

Conger, R. D., Cui, M., Bryant, C. M., \& Elder, G. H., Jr. (2000). Competence in early adult relationships: A developmental perspective on family influences. Journal of Personality and Social Psychology, 79, 224-237.
Connolly, J., Furman, W., \& Konarski, R. (2000). The role of peers in the emergence of heterosexual romantic relationships in adolescence. Child Development, 71, 1395-1408.

Connolly, J., \& Goldberg, A. (1999). Romantic relationships in adolescence: The role of friends and peers in their emergence and development. In B. B. Brown, C. C. Feiring, $\&$ W. Furman (Eds.), Contemporary perspectives on adolescent romantic relationships (pp. 266-290). Cambridge: Cambridge University Press.

Erikson, E. (1963). Childhood and society. New York: Norton.

Feeney, J. A. (1994). Attachment style, communication patterns and satisfaction across the life cycle of marriage. Personal Relationships, 1, 333-348.

Feeney, J. A., \& Noller, P. (1990). Attachment style as a predictor of adult romantic relationships. Journal of Personality and Social Psychology, 58, 281-291.

Feiring, C. (1996). Concepts of romance in fifteen-year-old adolescents. Journal of Research on Adolescence, 6, 181-200.

Feldman, S. S., Gowen, L. K., \& Fisher, L. (1998). Family relationships and gender as predictors of romantic intimacy in young adults: A longitudinal study. Journal of Research on Adolescence, 8, 263-286.

Furman, W. (1999). Friends and lovers: The role of peer relationships in adolescent romantic relationships. In W. A. Collins \& L. B. Laursen (Eds.), The Minnesota symposium on child psychology: Vol. 30. Relationships as developmental contents (pp. 133-154). Mahwah, NJ: Lawrence Erlbaum Associates.

Furman, W., \& Buhrmester, D. (1992). Age and sex differences in perceptions of networks of personal relationships. Child Development, 63, 103-115.

Furman, W., \& Wehner, E. A. (1994). Romantic views: Toward a theory of adolescent romantic relationships. In R. Montemayor, G. R. Adams, \& G. P. Gullota (Eds.), Advances in adolescent development: Vol. 6. Relationships during adolescence (pp. 237 288). Thousand Oaks, CA: SAGE Publications.

Furman, W., \& Wehner, E. A. (1997). Adolescent romantic relationships: A developmental perspective. New Directions for Child Development, 78, 21-35.

Havighurst, R. J. (1972). Developmental tasks and education (3rd ed.). New York: McKay.

Joyner, K., \& Campa, M. (2006). How do adolescent relationships influence the quality of romantic relationships in young adulthood? In A. Crouter \& A. Booth (Eds.), Romance and sex in emerging adulthood: Risks and opportunities (pp. 93-101). Mahwah, NJ Lawrence Erlbaum Associates.

Laursen, B. (1993). Conflict management among close peers. New Directions for Child Development, 60, 39-54.

Leaper, C. (1994). Exploring the consequences of gender segregation on social relationships. New Directions for Child Development, 65, 67-86.

Maccoby, E. E. (1995). The two sexes and their social systems. In P. Moen, G. H. Elder Jr., $\&$ K. Luescher (Eds.), Examining lives in context: Perspectives on the ecology of human development (pp. 347-364). Washington, DC: American Psychological Association.

Martin, B.(1990).The transmission of relationship difficulties from one generation to the next. Journal of Youth and Adolescence, 19, 181-199.

Nelson, D. A., \& Crick, N. R. (1999). Rose-colored glasses: Examining the social informationprocessing of prosocial young adolescents. Journal of Early Adolescence, 19, 17-387.

Noller, P., \& Feeney, J. A. (1998). Communication in early marriage: Responses to conflict, nonverbal accuracy, and conversational patterns. In T. N. Bradbury (Ed.), The de- 
velopmental course of marital dysfunction (pp. 11-43). New York: Cambridge University Press.

Petersen, A. C., Schulenberg, J., Abramowitz, R., Offer, D., \& Jarcho, H. (1984). A SelfImage Questionnaire for Young Adolescents (SIQYA): Reliability and validity studies. Journal of Youth and Adolescence, 13, 93-110.

Pistole, M. C. (1989). Attachment in adult romantic relationships: Style of conflict resolution and relationship satisfaction. Journal of Personality and Social Psychology, 6, 505-510.

Preacher, K. J., \& Leonardelli, G. J. (2001, March). Calculation for the Sobel test: An interactive calculation tool for mediation tests [Computer software]. Downloaded from http://www.psych.ku.edu/preacher/sobel/sobel.htm .

Reese-Weber, M., \& Bartle-Haring, S. (1998). Conflict resolution in family subsystems and adolescent romantic relationships. Journal of Youth and Adolescence, 27, 735-752.

Robins, R. W., Caspi, A., \& Moffitt, T. E. (2000). Two personalities, one relationship: Both partners' personality traits shape the quality of their relationship. Journal of Personality and Social Psychology, 79, 251-259.

Savin-Williams, R. C. (1996). Dating and romantic relationships among gay, lesbian, and bisexual youths. In R. C. Savin-Williams \& K. M. Cohen (Eds.), The lives of lesbians, gays, and bisexuals: Children to adults (pp. 166-180). Orlando, FL: Harcourt Brace.

Seiffge-Krenke, I., Shulman, S., \& Klessinger, N. (2001). Adolescent precursors of romantic relationships in young adulthood. Journal of Personality and Social Psychology, 18, 327-346.

Shulman, S., \& Scharf, M. (2000). Adolescent romantic behaviors and perceptions: Ageand gender-related differences and links with family and peer relationships. Journal of Research on Adolescence, 10, 99-118.

Simons, R. L., Lin, K., \& Gordon, L. C. (1998). Socialization in the family of origin and male dating violence: A prospective study. Journal of Marriage and the Family, 60, 467-478.

Sullivan, H. S. (1953). The interpersonal theory of psychiatry. New York: Norton.

Tallman, I., Burke, P. J., \& Gecas, V. (1998). Socialization into marital roles: Testing a contextual, development model of marital functioning. In T. N. Bradbury (Ed.), The developmental course of marital dysfunction (pp. 312-342). New York: Cambridge University Press.

Vicary, J. R., Klingaman, L. R., \& Harkness, W. L.(1995). Risk factors associated with date rape and sexual assault of adolescence girls. Journal of Adolescence, 18, 289-306.

von Salisch, M., \& Vogelgesang, J. (2005). Anger regulation among friends: Assessment and development from childhood to adolescence. Journal of Social and Personal Relationships, 22, 837-855.

Wood, J. T. (2000). Gender and personal relationships. In C. Hendrick \& S. S. Hendrick (Eds.), Close relationships: A sourcebook (pp. 301-313). Thousand Oaks, CA: SAGE Publications. 